\title{
Overpotential evaluation of PEMFC using semi-empirical equation and SEM
}

\author{
Yutaro Akimoto ${ }^{1, *}$, and Shin-nosuke Suzuki ${ }^{1}$ \\ ${ }^{1}$ Dept. of Innovative Electrical and Electronic Engineering at the National Institute of Technology, Oyama College, Japan.
}

\begin{abstract}
Fuel cells are a clean and weather-independent power supply. Solar and wind power are widespread in islands that are difficult to supply power. If problems are solved in the future, fuel cells are also expected to become popular. The widespread commercialization of PEMFC stacks depends on their reliability and fault diagnosis. In this study, we developed a degradation diagnosis method for the purpose of improving reliability. The output reduction of the fuel cell is separated into reduction factors called overpotentials. And the factor of the decrease is specified. In this paper, we show the proposed method and the degradation factors, and the effectiveness of the method.
\end{abstract}

\section{Introduction}

Fuel cells are a clean energy and weather-independent power device. If problems are solves in the future, fuel cells are also expected to become popular. One type of fuel cell, the proton-exchange membrane fuel cell (PEMFC), has low operation temperature and exhibits rapid start-up; therefore, it is used in not only cogeneration systems but also fuel cell vehicles (FCVs). The widespread commercialization of PEMFC stacks depends on their reliability and fault diagnosis.

The characteristic of PEMFC is shown by the relationship between its output voltage and current. It is called the $\mathrm{I}-\mathrm{V}$ curve and is used as an index of the performance of fuel cells and stacks. The output cell voltage determines the initial voltage, the activation overpotential due to reaction kinetics, ohmic overpotential due to ionic and electronic resistance, and concentration overpotential due to mass transport. These overpotentials are important to understand their effect on the reduction factor of the output of the fuel cell. Many methods have been proposed for separately determining these overpotentials using a I-V curve.

One method of calculating these overpotentials is by curve fitting using a semi-empirical equation. This method is fitted to the measured data and the value of the equation derived theoretically and experientially. There are simple, theoretical and complex equations to understand the voltage reduction factor such as cathode flooding [1-6].

Although the methods by curve fitting using a semiempirical equation can't predict the fuel cell performance outside the operation condition, they are useful to quickly predict it [7]. In the methods of previous studies, the fuel cell temperature was assumed to be steady during the operation. However, it is not constant in real fuel cell systems such as co-generation fuel cell stacks. Therefore, it is difficult to separate the different types of overpotentials on the polarization curve with varying fuel cell temperature in actual operation conditions by previous studies. In our previous study, we proposed a new semi-empirical equation considering the operation temperature of the fuel cell [8]. Through modelling of thermodynamic, mechanistic, and electrochemical, the initial voltage, the activation overpotential, ohmic overpotential, and concentration overpotential as a function of the operation temperature were expressed. In this study, the overpotentials were evaluated by semiempirical equation considering the operation temperature. Moreover, the MEA of best and worst output power in the stack were evaluated using scanning electron microscope (SEM). The relationship between the overpotentials and MEA condition were showed by these evaluations.

\section{Methodologies}

\subsection{Semi-Empirical Equation}

Generally, the output cell voltage, $V$, is expressed as follows:

$$
V=E_{0}-\eta_{\text {act }}-\eta_{\text {ohmic }}-\eta_{\text {con }}
$$

Where $E_{0}$ is the initial voltage. $\eta_{\text {act }}, \eta_{\text {ohmic }}$, and $\eta_{\text {con }}$ denote the activation overpotential due to reaction kinetics, ohmic overpotential due to ionic and electronic resistance, and concentration overpotential due to mass transport, respectively. These overpotentials are called overpotentials. Studying these losses is important to understand their effect on the reduction factor of the output of the fuel cell. Many methods have been proposed for separately determining these losses using a I-V curve.

\footnotetext{
* Corresponding author: akimoto@oyama-ct.ac.jp
} 
One method of calculating these losses is by curve fitting using a semi-empirical equation. Many equations are available from previous studies [1-6]. In our previous study, a new semi-empirical equation was proposed through thermodynamic, mechanistic and electrochemical [8]. The equation is described as:

$$
\begin{gathered}
V=E_{0(T)}-T[B+A \ln \{i\}]-b \frac{\Delta G}{R}-R_{\text {ohmic }(T)} \cdot i-m_{(T)} \exp \{n \cdot i\} \\
E_{0(T)}=E+\frac{\Delta \hat{s}}{n F}\left(T-T_{0}\right)-\frac{R T}{n F} \ln \left(\frac{a_{\mathrm{H}_{2} \mathrm{O}}}{a_{a} \llbracket a_{c}^{1 / 2}}\right)
\end{gathered}
$$$$
m(T)=1.1 \times 10^{-4}-1.2 \times 10^{-6}(T-273.15) \text { for } \mathrm{T}>312.15 \mathrm{~K}
$$$$
m(T)=3.3 \times 10^{-3}-8.2 \times 10^{-5}(T-273.15) \text { for } \mathrm{T}<312.15 \mathrm{~K}
$$

where $E$ denotes the standard-reversible voltage; $\Delta \hat{s}$ denotes the entropy of reaction; $n$ is the number of electrons transferred in the reaction; $F$ is Faraday's constant; $T$ is the fuel cell temperature; $T_{0}$ is the reference temperature; $R$ is the universal gas constant; and $a_{\mathrm{H} 2 \mathrm{O}}, a_{a}$, and $a_{c}$ denote the activities of water, anode gas, and cathode gas ; $A$ and $B$ denote the fitting parameter. Gibbs free energy, $\Delta G$ is assumed to be $237.2 \mathrm{~kJ} / \mathrm{mol}$ [9]. respectively. Through thermodynamics, these parameters are obtained from the previous work under the following experimental [2]: $E=1.229 \mathrm{~V}, \Delta \hat{s}=-163.23 \mathrm{~J} / \mathrm{mol} \mathrm{K}, n$ $=2, F=96485.35 \mathrm{C} / \mathrm{mol}, T_{0}=298.15 \mathrm{~K}, R=8.314 \mathrm{~J} / \mathrm{mol}$ $\mathrm{K}, a_{\mathrm{H} 2 \mathrm{O}}=1, a_{a}=0.1, a_{c}=0.21$ (Air) or $1\left(\mathrm{O}_{2}\right)$.

\subsection{SEM}

The information of microstructure, porosity, pore size distribution and interconnectedness is gleaned from microscopy. Scanning electron microscopy (SEM) uses a focused beam of high-energy electrons to generate a variety of signals at the surface of solid specimens and is often applied to PEMFC. In the previous study, the degradation of sealing in test cycle was shown [10]. In this study, the thicknesses of membrane and catalyst layer in cell on PEMFC stack were compared. Moreover, the relationship between the overpotentials and MEA were showed by these evaluations.

\section{Experimental and operation conditions}

Fig. 1 shows the picture of air-cooled 5-cells PEMFC stack. The experiments were performed using this stack. This stack comprised 5 cells connected in series, and the cells were numbered 1-5 starting from the side of the hydrogen inlet. The fuel cell system is shown in figure 2 . Hydrogen $(>99.99 \%)$ and air supplied without humidification, and the flow rate was measured using a digital flow meter. A 160-kW DC electric load (Takasago: FK-160L2Z) was used for all experiments aimed at evaluating the fuel cell stack performance. The stack was operated at a constant current, and the cell voltages were measured using a data logger (HIOKI: LR8431). The electronic load performs constant current operation and is swept in increments of $0.1 \mathrm{~A}$ from OCV to $1 \mathrm{~A}$, in $1 \mathrm{~A}$ up to $9 \mathrm{~A}$ in $1 \mathrm{~A}$ increments. In this study, the supplied hydrogen and air flow rate was 1.8 and $5.0 \mathrm{~L} / \mathrm{min}$ and operation temperature of fan are 30,40 and $50^{\circ} \mathrm{C}$.

For fitting the measured data and the equations, we used the multiple linear regression function of "Microsoft Office Excel 2010". The Regression Analysis tool in Excel performs linear regression analysis by using the least squares method to fit a line thorough a set of data.

SEM (JEOL: JSM7800F) was used for measurement of thickness of membrane and catalyst layer. The image was analyzed Energy Dispersive Spectrometer (JEOL: JED2300) for distinction each element. The thickness was measured ten points of each area such as upper, middle and lower at slice of MEA.

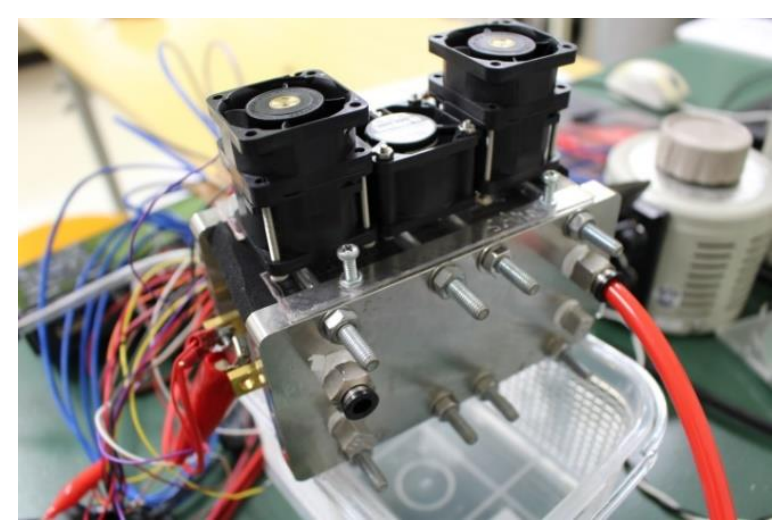

Fig. 1. Picture of 5-cells PEMFC stack

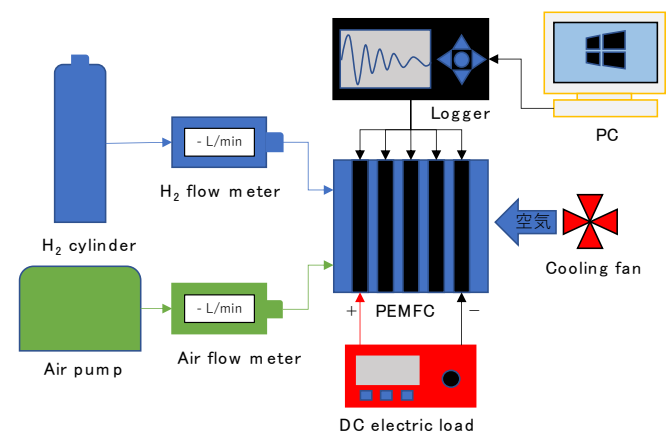

Fig. 2. Schematic diagrams of fuel cell system

\section{Results and Discussions}

\subsection{Overpotential evaluation of Semi-Empirical Equation}

Fig. 3 shows the $\mathrm{I}-\mathrm{V}$ curve of each cell at $40{ }^{\circ} \mathrm{C}$. The voltage of at cell No. 5 decreased until $0.27 \mathrm{~V}$ at $9 \mathrm{~A}$. The performance of cell No.5 was worst of this stack and this trend doesn't change at each operational condition.

Fig. 4 shows the I-V curve of cell No.3 and No.5 at each operational temperature. The cell No.3 doesn't change at each condition, however, the voltage of cell No.5 decreased until $0.15 \mathrm{~V}$ at $30^{\circ} \mathrm{C}$. At this condition, the cell 
was considered to become the flooding because generated water was easy to accumulate in the fuel cell.

Fig. 5 shows the results of overpotential of cell No.3 and No.5. The ohmic overpotential of cell No.3 was higher than cell No.5. The difference of these cells was $0.13,0.07$ and $0.06 \mathrm{~V}$ at each temperature. The activation overpotential of cell No.3 was lower than cell No.5. The difference of these cells was $0.26,0.18$ and $0.16 \mathrm{~V}$ at each temperature. This trend didn't change at each condition. Therefore, the performance considered the degradation of parts of PEMFC such as membrane and catalyst layer. The concentration overpotential was difficult to appear the degradation of parts of PEMFC due to mass transport. In this study, we try to evaluate the ohmic and activation overpotential and compare the result of Semi-Empirical Equation and SEM.

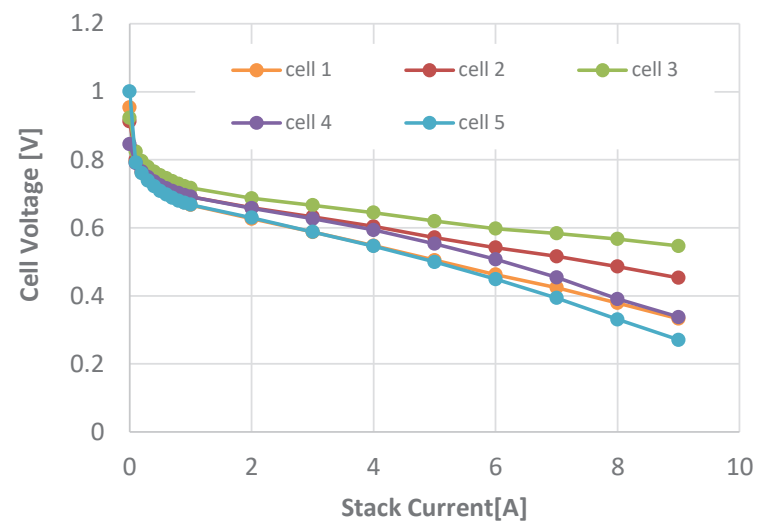

Fig. 3. I-V curve of each cell at $40{ }^{\circ} \mathrm{C}$

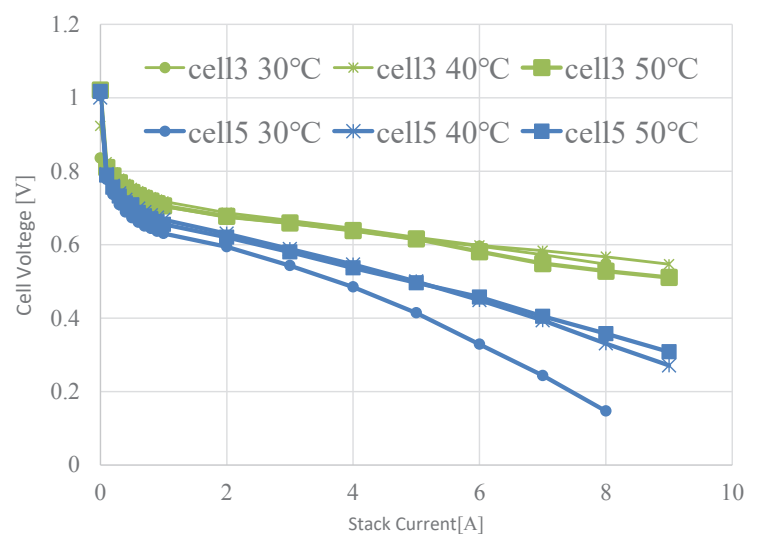

Fig. 4. I-V curve at cell No.3 and No.5

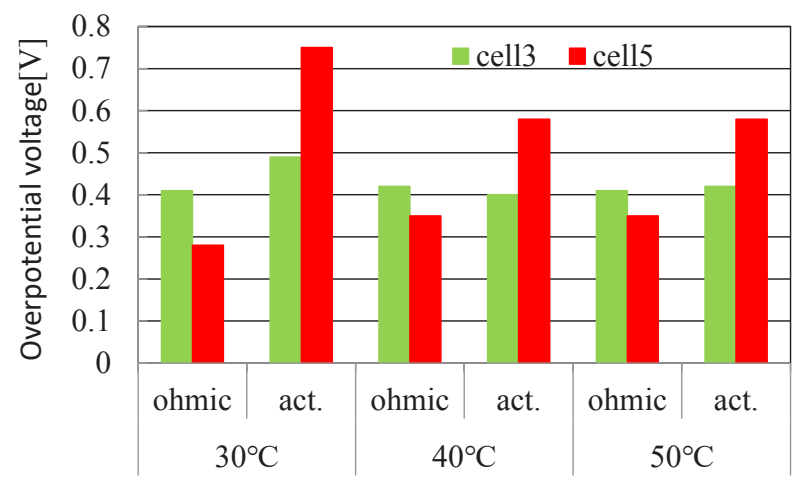

Fig. 5. Overpotentials of each operation temperature

\subsection{Comparison evaluation of MEA thickness and Overpotential}

Fig. 6 shows the SEM topographies of the slice of MEA. The thickness of MEA was measured and analysed by SEM. Fig. 7 and 8 shows the average thickness of the membranes and catalyst layers. The results of layer were average of anode and cathode data. The membrane of No. 3 was thicker than No. 5 at all area. The average catalyst layer of No. 3 was $0.66 \mu \mathrm{m}$ thinner than No. 5 .

Fig. 9 shows the comparison result of overpotential and thickness measurement by SEM. In the ohmic overpotential, the membrane resistance tends to dominate because ionic charge transport tends to be more difficult than electronic charge transport. Therefore, resistance of No.5 was low by the degradation.

The performance of catalyst affects the activation overpotential. The average catalyst layer of No. 5 was thinner than No.3. Therefore, the performance of cell No. 5 was low because the catalyst layer became thin due to degradation.

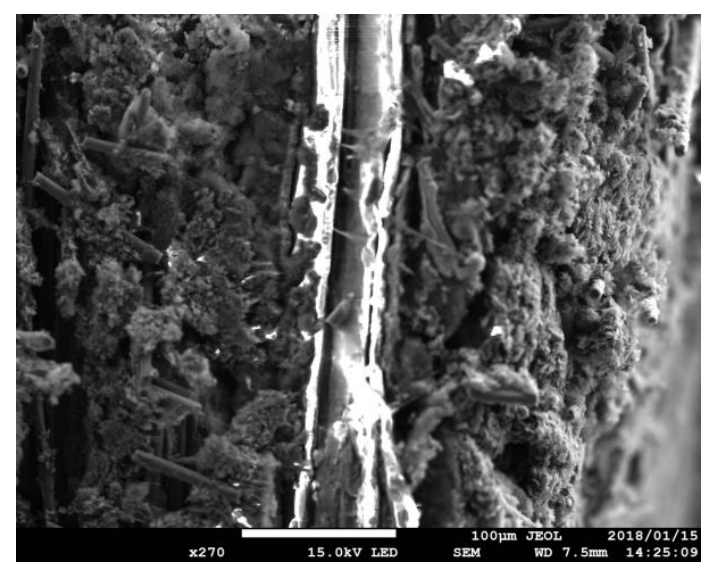

Fig. 6. SEM topographies of the slice of MEA 


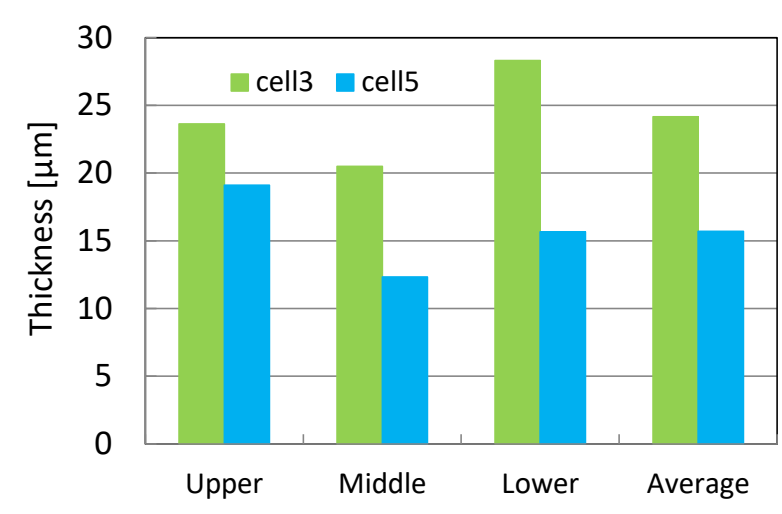

Fig. 7. Thickness of membrane

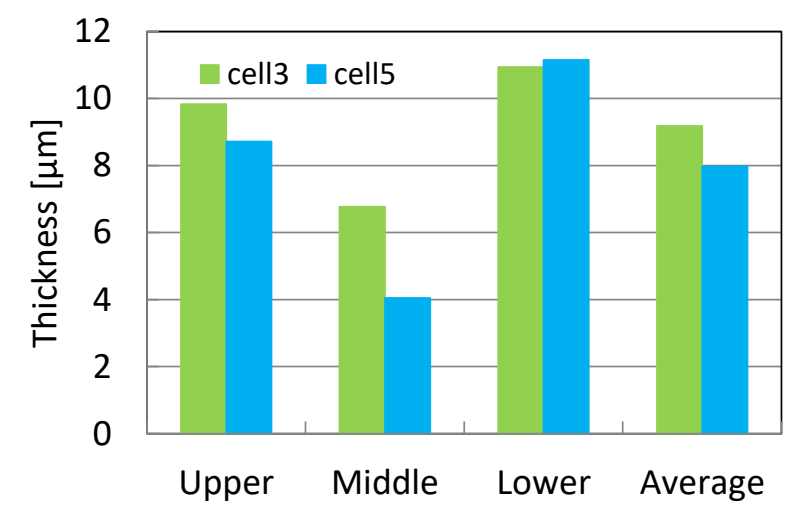

Fig. 8. Thickness of catalyst layer

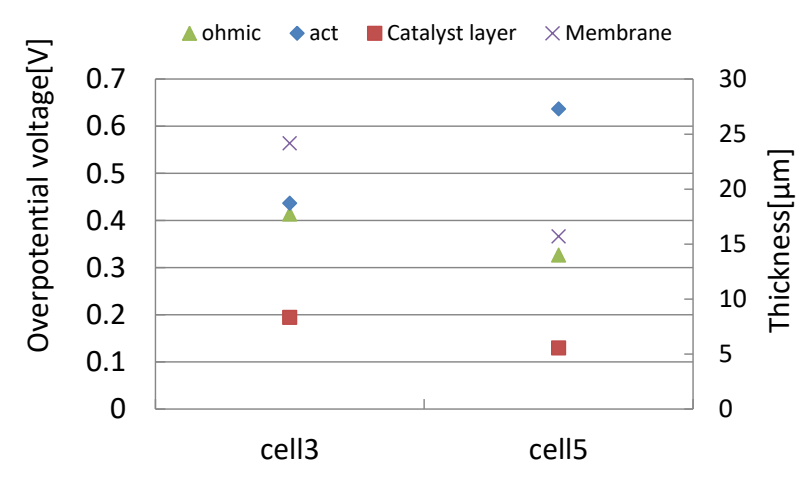

Fig. 9. Comparison result of overpotential and thickness by SEM

\section{Conclusions}

In this study, the overpotentials were evaluated by semiempirical equation considering the operation temperature. Moreover, the MEA of best and worst performance in the stack were evaluated using scanning electron microscope (SEM). The relationship between the overpotentials by our proposed equation and MEA condition were showed by these evaluations.

The voltage of at cell No. 5 decreased until $0.27 \mathrm{~V}$ at 9 A. The performance of cell No.5 was worst of this stack and this trend doesn't change at each operational condition. At $30^{\circ} \mathrm{C}$, the cell No.3 doesn't change on each condition, however, the voltage of cell No.5 decreased until $0.15 \mathrm{~V}$ At this condition, the cell was considered to become the flooding because generated water was easy to accumulate in the fuel cell.

The ohmic overpotential of cell No.3 was higher than cell No.5 and the activation overpotential of cell No.3 was lower than cell No.5. This trend doesn't change at each condition. Therefore, the performance considered the degradation of parts of PEMFC such as membrane and catalyst layer.

By the SEM analysis, the membrane of No. 3 was thicker than No. 5 at all area. The average catalyst layer of No. 3 was $0.66 \mu \mathrm{m}$ thinner than No. 5 .

In the ohmic overpotential, the membrane resistance tends to dominate because ionic charge transport tends to be more difficult than electronic charge transport. Therefore, resistance of No.5 was low by the degradation.

The performance of catalyst affects the activation overpotential. The average catalyst layer of No. 5 was thinner than No.3. Therefore, the performance of cell No. 5 was low because the catalyst layer became thin due to degradation.

From these results, the proposed semi-empirical equation was found to provide the degradation condition of membrane and catalyst layer. Moreover, the study showed possibility to use as non-destructive approach.

This work was supported by JSPS KAKENHI Grant Number JP17K14650.

\section{References}

1. J. Kim, S.M.Lee, S.Srinivasan, G.Burbuoi, Modeling of Proton Exchange Membrane Fuel Cell Performance with an Empirical Equation. J. Electrochem. Soc. 142, 2670-2674, (1995)

2. S. Haji, Analytical Modeling of PEM Fuel Cell i-V Curve. Renew.Energ. 36, 451-458, (2011)

3. T.E. Springer, T.A. Zawodzinski, S. Gottesfeld, Polymer Electrolyte Fuel Cell Model. J. Electrochem. Soc. 138, 2334-2342, (1991)

4. J.C. Amphlett, R.M.Baumert, R.F. Mann., B.A. Peppley, P.R.Roberge, Performance Modeling of the Ballard Mark IV Solid Polymer Electrolyte Fuel Cell I. Mechanistic Model Development. J. Electrochem. Soc. 142, 1-8, (1995)

5. G. Squadrito, G. Maggio,E. Passalacqua, F. Lufrano, A.Patti, An Empirical Equation for Polymer Electrolyte Fuel Cell (PEFC) Behavior. J. Appl. Electrochem. 29, 1449-1455, (1999)

6. L. Pisani, G. Murgia, M. Valentini, B.A D’Aguanno, New Semi-Empirical Approach to Performance Curves of Polymer Electrolyte Fuel Cells. J. Power Sources 108, 192-203, (2002).

7. D. Chaddie, N. Munroe, Review of Comparison of Approaches to Proton Exchange Membrane Fuel Cell Modeling. J. Power Sources, 147, 72-84, (2005)

8. Y. Akimoto, K. Okajima, Semi-empirical equation of PEMFC considering operation temperature, Energy Technology \& Policy, 1-1, 91-96, (2014)

9. James, Larmine; Andrew, Dicks. Fuel Cell Systems Explained. Wiley: West Sussex, (2003). 
10. M. Schulze, M. Knöri, A. Knöri, E. Gülzow, Degradation of sealings for PEFC test cells during fuel cell operation, J. of Power Sources, 127, 1-2, 222-229, (2004) 